\title{
Editorial
}

\section{Is there a future for revenue management?}

Journal of Revenue and Pricing Management (2015) 14, 1-2. doi:10.1057/rpm.2014.40

Revenue Management is a positivist paradigm, a value system drive by logic and mathematical treatments. It is a world of rationality in order to make sense of endless decision points. In one of the articles published in this issue, Academic Revenue Management and Quantitative Worship by Collins and Frydenlund, piece is centred on the recent debate about the practical application of academic revenue management. The concern of practitioners is that any approach they employ must be appealing to higher management, thus there is demand for simple and clear approaches to revenue management. Central to the authors arguments is: if academic revenue management is going to survive its growing pains to become an established field, it needs to remember its purpose. If it is no longer useful to the practitioner community, it will die or get absorbed into an older, more established academic subject. This article argues that one way to stop this trend is to embrace other research approaches to present a multidisciplinary perspective loyal to the roots of Operations Research and revenue management. This a challenging and thought-provoking piece.

Anderson and colleagues tackle the classic news vendor problem in the context of a modern society. The basic Newsvendor premise involves a seller of a perishable good facing an uncertain demand. In opaque selling certain characteristics of the product or service are hidden from the consumer until after purchase, transforming a differentiated good into somewhat of a commodity. Opaque selling has become popular in travel service pricing, as it allows firms to sell their differentiated products at higher prices to regular brand loyal customers while simultaneously selling to non-loyal customers at discounted prices. The authors investigate the impacts of Priceline.com changes upon optimal prices and inventory allocation policies. The model is empirically illustrated using Priceline data for a 3.5-star hotel. Yu consider a joint pricing-inventory decision problem for horizontally differentiable products that require common resources to produce, procure or hold formulating, and analyses a joint pricing and inventory problem for two horizontally differentiated products sharing a common resource. Demand is stochastic with additive uncertainty, price-based substitutable and lost if not satisfied immediately. Through the analysis of multi-dimensional strict quasiconcavity of the profit function, the author proves that there exists a unique optimal solution to the problem. Hetrakul and Cirillo proposition that choice models based on random utility theory are being used in revenue management problems because of their ability to deal with customer heterogeneity and preferences. The application of Revenue Management in the railway industry configure discrete and random mixtures of logit through a model ticket purchase timing over a finite sale horizon; in particular, parametric and nonparametric mixed logit are formulated and estimated. Results show that up to 20 per cent increase in revenue can be obtained when methodologies based on customer heterogeneity are considered.

Yeoman alludes to how business use of free pricing and when free is actually not free (if you 
know what I mean). Ødegaard ponders Revenue Management from a customer perspective. For the average personal traveller, airfare pricing has some peculiar and unpredictable features. These features may unnecessarily complicate matters for customers in their decision making over whether. The objective of the thoughts piece is to raise the issue whether airlines potentially could be better off by sharing explicitly with their customers what causes these peculiarities to purchase a given ticket or not.

And finally, happy new year.

Ian Yeoman

Editor 